\title{
Analysis and Control of Offshore Wind Farms Connected with Diode Rectifier based HVDC System
}

\author{
Lujie Yu, Rui Li, and Lie Xu, Senior Member, IEEE, Grain P. Adam, Member, IEEE
}

\begin{abstract}
This paper analyzes the control and operation of offshore wind farms connected with diode rectifier based HVDC (DR-HVDC) system. A small-signal state-space model of the offshore wind turbines (WTs) connected with DR-HVDC system is developed to design the WT $Q-f$ droop control. The use of WT $P$ $V$ and $Q-f$ control during individual WT active power variation is clearly clarified. In order to reduce the interaction between WT active power and reactive power, an angle feedforward control is proposed where an additional phase shift is directly added to the WT output voltage based on the WT's active power output. The effectiveness of the proposed control on improving dynamic response and reducing active and reactive power interaction is verified by frequency-domain analysis and time-domain simulations in PSCAD/EMTDC.
\end{abstract}

Index Terms - diode rectifier based HVDC, interaction of WT active and reactive power, small-signal analysis, wind turbine control

\section{INTRODUCTION}

$\mathrm{F}$ or connecting large wind power plants, high voltage direct current (HVDC) transmission provides numerous advantages over AC systems, such as no reactive power in transmission cables, lower power losses and cost [1]-[3]. Recently, diode rectifier based HVDC (DR-HVDC) transmission has drawn attentions from industry and research community, particularly for connection of offshore wind farm [4]-[7]. Comparing with voltage source converter based HVDC (VSC-HVDC), the transmission loss, volume and total cost of the DR-HVDC can be potentially decreased by $20 \%, 80 \%$ and $30 \%$, respectively [7].

Control of fully rated converter wind turbine (WT) using low bandwidth communication was proposed in [8] for DR-HVDC system. Based on the analysis when the offshore wind farm is simplified as one aggregated WT, its active current is used to establish the offshore wind farm point of coupling (PCC) voltage magnitude while reactive current is used to establish wind farm PCC frequency. This control is further developed for the DR-HVDC system considering many parallel WTs in [9][11], where each WT shares the required active and reactive currents to support the wind farm PCC AC voltage and frequency according to each WT power rating. In [12]-[17], a distributed $P-V$ and $Q-f$ droop control without the use of

This work was supported by the European Union's Horizon 2020 research and innovation programme under Grant 691714.

L. Yu is with the School of Electrical and Information Engineering, Tianjin University, Tianjin, 300072, China (e-mail: lujie.yu@outlook.com).

R. Li, L. Xu, and G. P. Adam are with the Department of Electronic and Electrical Engineering, University of Strathclyde, Glasgow, G1 1XW, UK (email: rui.li@strath.ac.uk, lie.xu@strath.ac.uk, grain.adam@strath.ac.uk). communication was proposed to allow the stable operation of offshore WTs under DR-HVDC system. This control enables many WTs to form the offshore network together based on local variables and behave as distributed AC voltage sources.

However, no detailed analysis has been conducted for the adoption and design of the $Q-f$ droop control. In addition, how the $P-V$ and $Q-f$ droop controls interact and affect WT active power, reactive power and the phase angle change in the inductive impedance network has not been clarified.

This paper focuses on the analysis of WT control and explores the potential problems in the existing design of WT $P$ $V$ and $Q-f$ control. Based on the in-depth analysis, an improved WT control method is proposed to reduce the strong interaction between WT active and reactive power. The main contributions are summarized as:

- A small-signal model of DR-HVDC system is developed. Based on the small-signal model, stability analysis is conducted to design the $Q-f$ droop control.

- $\quad$ The mechanism of how the WT $P-V$ and $Q-f$ droop control drives the phase angle change during WT active power variation is clearly clarified.

- An angle feedforward control is proposed to reduce the interaction between WT active power and reactive power, which effectively reduces the variations of offshore $\mathrm{AC}$ voltage and reactive power during active power change. The effectiveness of the proposed control is verified by frequency-domain analysis and time-domain simulation results.

The rest of this paper is organized as follows. In Section II, the layout of offshore wind farm connected with DR-HVDC system and the WT control is introduced. Small-signal model of the system is developed in Section III. Section IV presents the design and analysis of $Q-f$ droop control. In Section $\mathrm{V}$, an angle feedforward control is proposed to reduce the interaction between WT active and reactive power, and finally Section VI draws conclusions.

\section{STRUCTURE OF DR-HVDC SYSTEM}

Fig. 1 shows a $1000 \mathrm{MW}$ offshore wind farm connected with DR-HVDC. The offshore diode rectifier is made up of a 12pulse bridge, while the onshore inverter uses modular multilevel converter (MMC) which controls the DC voltage of the DR-HVDC link. Considering both accuracy and simulation speed, the offshore wind farm is represented as 10 strings, each with 4 aggregated WTs rated at $25 \mathrm{MW}$. As the focus of this study is the analysis of the offshore wind farm connected with 


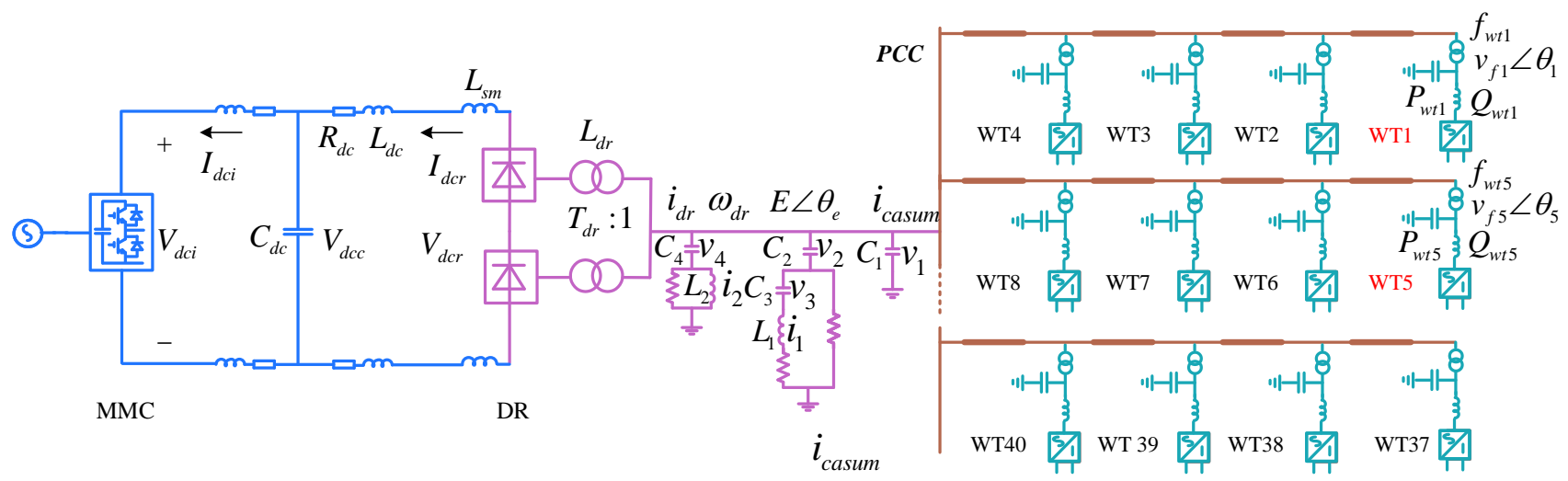

Fig. 1 Structure of offshore wind farm connected with DR-HVDC.

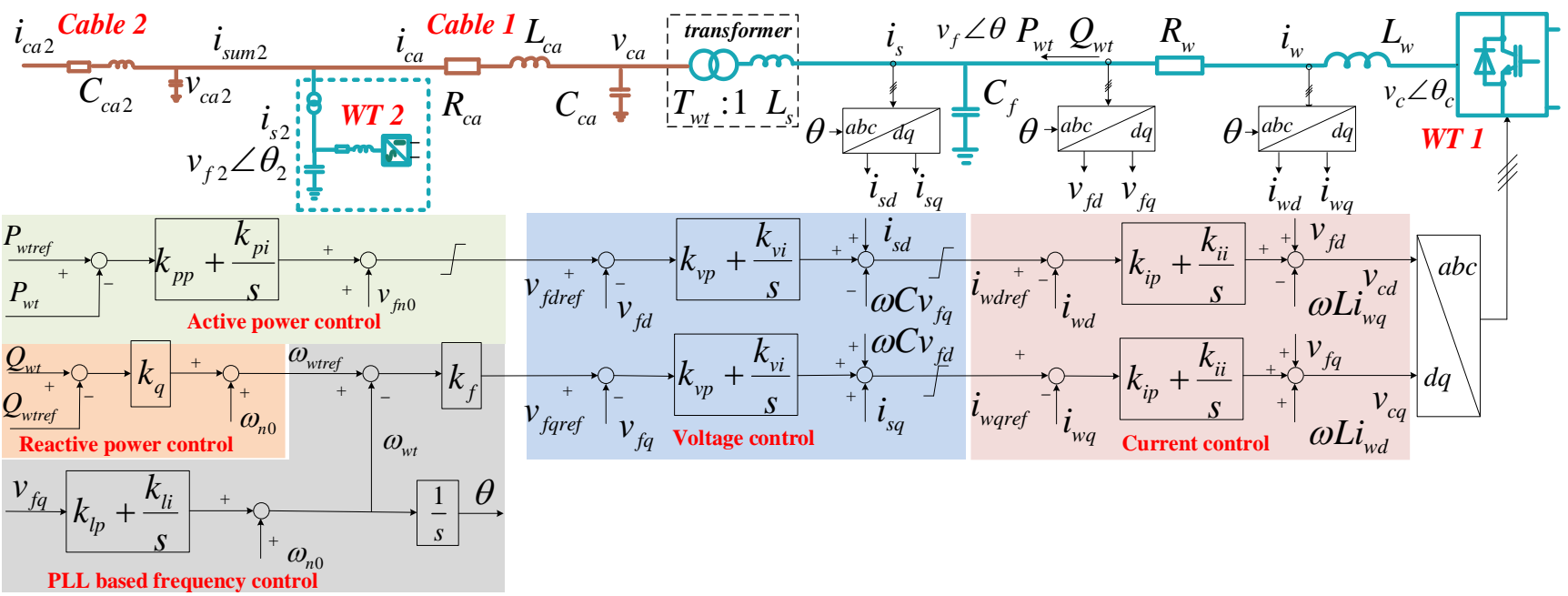

Fig. 2 Distributed control of WT line-side converter in offshore wind farm connected with DR-HVDC

DR-HVDC, onshore MMC is simplified as a constant DC source [8]-[9]. The system parameters are shown in Table I in the Appendix. A. Fig. 2 shows the overall control structure of the WT line-side converters, considering that the WT DC voltage is controlled by the WT generator side converter [8][17].

\section{Small Signal Modelling OF THE OFFSHORE WIND FARMS CONNECTED WITH DR-HVDC}

In order to analyse the stability of the WTs connected with DR-HVDC, a small-signal model, including diode rectifier, diode rectifier transformer inductance, DC smoothing reactance, HVDC cable, diode rectifier filter, WT, WT LC filter, WT transformer and AC cable is derived. Nonlinear equations that describe the system dynamics are linearized at an operating point based on $d q$ rotating reference frame. Such an accurate and detailed small-signal model of WTs connected with DR-HVDC has not be presented before.

\section{A. Small-signal model of diode rectifier}

The offshore DC voltage of DR-HVDC link $V_{d c r}^{\prime}$, without considering the dynamic of the transformer inductance, is expressed as

$$
V_{d c r}^{\prime}=\left[6 \sqrt{3} T_{d r}\left(e_{d}^{2}+e_{q}^{2}\right)^{0.5}-6 \omega_{d r} L_{d r} I_{d c r}\right] / \pi
$$

where $\omega_{d r}$ is the offshore PCC frequency; $e_{d}$ and $e_{q}$ are the $d$ and $q$-axis components of offshore PCC voltage; $I_{d c r}$ is the DC current; $T_{d r}$ and $L_{d r}$ are the turn ratio and inductance of the diode rectifier transformer.

Linearizing (1) yields the offshore DC voltage deviation

$$
\Delta V_{d c r}^{\prime}=k_{i} \Delta \omega_{d r}+k_{j} \Delta e_{d}+k_{k} \Delta e_{q}+k_{l} \Delta I_{d c r}
$$

where

$$
\begin{aligned}
& k_{i}=\partial V_{d c r}^{\prime} / \partial \omega_{d r}=-6 L_{d r} I_{d c r 0} / \pi \\
& k_{j}=\partial V_{d c r}^{\prime} / \partial e_{d}=6 \sqrt{3} T_{d r} e_{q 0} /\left(\pi \sqrt{\left(e_{d 0}^{2}+e_{q 0}^{2}\right)}\right) \\
& k_{k}=\partial V_{d c r}^{\prime} / \partial e_{q}=6 \sqrt{3} T_{d r} e_{d 0} /\left(\pi \sqrt{\left(e_{d 0}^{2}+e_{q 0}^{2}\right)}\right) \\
& k_{l}=\partial V_{d c r}^{\prime} / \partial I_{d c r}=-6 \omega_{d r 0} L_{d r} / \pi
\end{aligned}
$$

Assuming the diode rectifier is lossless, its active power injected from $\mathrm{AC}$ equals to the $\mathrm{DC}$ power:

$$
1.5\left(e_{d} i_{d}+e_{q} i_{q}\right)=V_{d c r}^{\prime} I_{d c r}
$$

where $i_{d}$ and $i_{q}$ are the $d$ - and $q$-axis components of diode rectifier AC current $i_{d r}$. Linearizing (4) yields the active power deviation

$$
\begin{aligned}
& 1.5\left(e_{d 0} \Delta i_{d}+\Delta e_{d} i_{d 0}+e_{q 0} \Delta i_{q}+\Delta e_{q} i_{q 0}\right) \\
& =\Delta V_{d c r}^{\prime} I_{d c r 0}+V_{d c r 0}^{\prime} \Delta I_{d c r}
\end{aligned}
$$


Substituting the offshore DC voltage deviation $\Delta V^{\prime}{ }_{d c r}$ depicted as (2) into (5), the following equation is derived:

$$
\begin{aligned}
& 1.5\left(e_{d 0} \Delta i_{d}+e_{q 0} \Delta i_{q}\right)=k_{i} I_{d c r 0} \Delta \omega_{d r}+\left(k_{j} I_{d c r 0}-1.5 i_{d 0}\right) \Delta e_{d} \\
& +\left(k_{k} I_{d c r 0}-1.5 i_{q 0}\right) \Delta e_{q}+\left(k_{l} I_{d c r 0}+V_{d c r 0}^{\prime}\right) \Delta I_{d c}
\end{aligned}
$$

On the other hand, the reactive power consumption of the diode rectifier equals to the reactive power injected from the AC:

$$
1.5\left(-e_{d} i_{q}+e_{q} i_{d}\right)=V_{d c r}^{\prime} I_{d c r} g(\mu)
$$

where

$$
\begin{aligned}
& g(\mu)=(2 \mu-\sin 2 \mu) /(1-\cos 2 \mu) \\
& \mu=\arccos \left[1-2 \omega_{d r} L_{d r} I_{d c r} /\left(\sqrt{3\left(e_{d}^{2}+e_{q}^{2}\right)} T_{d r}\right)\right] .
\end{aligned}
$$

Linearizing (7) yields the reactive power deviation

$$
\begin{aligned}
& 1.5\left(e_{q 0} \Delta i_{d}-e_{d 0} \Delta i_{q}\right)=\Delta V_{d c r}^{\prime} I_{d c r 0} g\left(\mu_{0}\right)+V_{d c r 0}^{\prime} \Delta I_{d c r} g\left(\mu_{0}\right) \\
& +V_{d c r 0}^{\prime} I_{d c r 0} \Delta g+1.5 i_{q 0} \Delta e_{d}-1.5 i_{d 0} \Delta e_{q}
\end{aligned}
$$

where

$$
\begin{aligned}
& \Delta g=z_{1} \Delta \omega_{d r}+z_{2} \Delta e_{d}+z_{3} \Delta e_{q}+z_{4} \Delta I_{d c r} \\
& z_{1}=b \partial \mu / \partial \omega_{d r}=2 b L_{d r} I_{d c r} /\left(\sqrt{3\left(e_{d 0}^{2}+e_{q 0}^{2}\right)} T_{d r} \sin \mu_{0}\right) \\
& \left.z_{2}=b \partial \mu / \partial e_{d}=-2 b \omega_{d r 0} L_{d r} I_{d c r 0} e_{q 0} /\left(\sqrt{3} T_{d r} \sin \mu_{0}\left(e_{d 0}{ }^{2}+e_{q 0}\right)^{2}\right)^{1.5}\right) \\
& \left.z_{3}=b \partial \mu / \partial e_{q}=-2 b \omega_{d r 0} L_{d r} I_{d c r 0} e_{d 0} /\left(\sqrt{3} T_{d r} \sin \mu_{0}\left(e_{d 0}{ }^{2}+e_{q 0}\right)^{2}\right)^{1.5}\right) \\
& z_{4}=b \partial \mu / \partial I_{d c r}=2 b \omega_{d r 0} L_{d r} /\left(\sqrt{3\left(e_{d 0}{ }^{2}+e_{q 0}{ }^{2}\right)} T_{d r} \sin \mu_{0}\right) \\
& b=(\partial g / \partial \mu)=\left[2-2\left(2 \mu_{0}-\sin 2 \mu_{0}\right) \sin 2 \mu_{0} /\left(1-\cos 2 \mu_{0}\right)^{2}\right]
\end{aligned}
$$

Substituting (2) into (9) and combining with (6), the $d$ - and $q$ axis components of diode rectifier AC current deviation are expressed as

$$
\left\{\begin{array}{l}
\Delta i_{d}=k_{a} \Delta \omega_{d r}+k_{b} \Delta e_{d}+k_{c} \Delta e_{q}+k_{d} \Delta I_{d c r} \\
\Delta i_{q}=k_{e} \Delta \omega_{d r}+k_{f} \Delta e_{d}+k_{g} \Delta e_{q}+k_{h} \Delta I_{d c r}
\end{array}\right.
$$

where

$$
\begin{aligned}
& \int k_{a}=m\left(k_{i} I d c 0 e_{d 0}+k_{i} I_{d c r} g\left(\mu_{0}\right) e_{q 0}+z_{1} V_{d c r 0}^{\prime} I_{d c r 0} e_{q 0}\right) \\
& k_{b}=m\left(k_{j} I_{d c r 0} e_{d 0}-1.5 i_{d 0} e_{d 0}+k_{j} I_{d c r 0} g\left(\mu_{0}\right) e_{q 0}+z_{2} V_{d c r 0}^{\prime} I_{d c r 0} e_{q 0}+1.5 i_{q 0} e_{q 0}\right) \\
& k_{c}=m\left(k_{k} I_{d c r 0} e_{d 0}-1.5 i_{q 0} e_{d 0}+k_{k} I_{d c r 0} g\left(\mu_{0}\right) e_{q 0}+z_{3} V_{d c r 0}^{\prime} I_{d c r 0} e_{q 0}-1.5 i_{d 0} e_{q 0}\right) \\
& k_{d}=m\left(k_{l} I_{d c r 0} e_{d 0}+V_{d c r 0}^{\prime} e_{d 0}+k_{l} I_{d c r 0} g\left(\mu_{0}\right) e_{q 0}+z_{4} V_{d c r 0}^{\prime} I_{d c r 0} e_{q 0}+V_{d c r 0}^{\prime} g\left(\mu_{0}\right) e_{q 0}\right) \\
& \left\{k_{e}=m\left(k_{i} I_{d c r 0} e_{q 0}-k_{i} I_{d c r} g\left(\mu_{0}\right) e_{d 0}-z_{1} V_{d c r o}^{\prime} I_{d c r} e_{d 0}\right)\right. \\
& k_{f}=m\left(k_{l} I_{d c r 0} e_{q 0}-1.5 i_{d 0} e_{q 0}-k_{l} I_{d c r} g\left(\mu_{0}\right) e_{d 0}-z_{2} V_{d c r 0}^{\prime} I_{d c 0} e_{d 0}-1.5 i_{q 0} e_{d 0}\right) \\
& k_{g}=m\left(k_{k} I_{d c r 0} e_{q 0}-1.5 i_{q 0} e_{q 0}-k_{k} I_{d c r 0} g\left(\mu_{0}\right) e_{d 0}-z_{3} V_{d c r 0}^{\prime} I_{d c r 0} e_{d 0}+1.5 i_{d 0} e_{d 0}\right) \\
& k_{h}=m\left(k_{l} I_{d c r} e_{q 0}+V_{d c r}^{\prime} e_{q 0}-k_{l} I_{d c r} g\left(\mu_{0}\right) e_{d 0}-z_{4} V_{d c r 0}^{\prime} I_{d c 0} e_{d 0}-V_{d c r}^{\prime} g\left(\mu_{0}\right) e_{d 0}\right) \\
& \left.m=\left(1.5 e_{d 0}{ }^{2}+1.5 e_{q 0}\right)^{2}\right)^{-1}
\end{aligned}
$$

From (2) and (11), the small-signal model of diode rectifier HVDC station is expressed as

$$
\left[\begin{array}{c}
\Delta i_{d} \\
\Delta i_{q} \\
\Delta V_{d c r}^{\prime}
\end{array}\right]=\left[\begin{array}{cccc}
k_{a} & k_{b} & k_{c} & k_{d} \\
k_{e} & k_{f} & k_{g} & k_{h} \\
k_{i} & k_{j} & k_{k} & k_{l}
\end{array}\right]\left[\begin{array}{c}
\Delta \omega_{d r} \\
\Delta e_{d} \\
\Delta e_{q} \\
\Delta I_{d c r}
\end{array}\right]
$$

B. Small-signal model of DR transformer inductance, DR DC smoothing reactance and HVDC cable

The dynamics of the DR transformer inductance were not considered in the small signal model presented in (13). Taking into account the transformer inductance dynamics, (1) is modified as [18]-[20]

$$
V_{d c r}=V_{d c r}^{\prime}-4 L_{d r} d I_{d c r} / d t
$$

On the other hand, the DC smoothing reactance $L_{s m}$ and HVDC cable (considered as a $\mathrm{T}$ model) as shown in Fig. 1 are represented as

$$
\begin{aligned}
& \left(2 L_{s m}+2 L_{d c}\right) d I_{d c r} / d t+2 R_{d c} I_{d c r}+V_{d c c}=V_{d c r} \\
& C_{d c} d V_{d c c} / d t=I_{d c r}-I_{d c i} \\
& 2 L_{d c} d I_{d c i} / d t+2 R_{d c} I_{d c i}+V_{d c i}=V_{d c c}
\end{aligned}
$$

Substituting (14) into (15), the dynamics of the transformer inductance, DC smoothing reactance and HVDC cable are expressed as

$$
\begin{aligned}
& \left(4 L_{d r}+2 L_{s m}+2 L_{d c}\right) d I_{d c r} / d t+2 R_{d c} I_{d c r}+V_{d c c}=V_{d c r}^{\prime} \\
& C_{d c} d V_{d c c} / d t=I_{d c r}-I_{d c i} \\
& 2 L_{d c} d I_{d c i} / d t+2 R_{d c} I_{d c i}+V_{d c i 0}=V_{d c c}
\end{aligned}
$$

Linearizing at the operating point, its small-signal model is expressed as

$$
\left[\begin{array}{c}
\dot{\Delta}_{d c r} \\
\dot{\Delta}_{d c i} \\
\Delta \dot{V}_{d c c}
\end{array}\right]=\left[\begin{array}{ccc}
-2 R_{d c} / L_{e q} & 0 & -1 / L_{e q} \\
0 & -R_{d c} / L_{d c} & 1 / 2 L_{d c} \\
1 / C_{d c} & -1 / C_{d c} & 0
\end{array}\right]\left[\begin{array}{c}
\Delta I_{d c r} \\
\Delta I_{d c i} \\
\Delta V_{d c c}
\end{array}\right]+\left[\begin{array}{c}
1 / L_{e q} \\
0 \\
0
\end{array}\right] \Delta V_{d c r}^{\prime}
$$

where $L_{e q}=4 L_{d r}+2 L_{s m}+2 L_{d c}$.

The small-signal model of the DR-HVDC link considering the dynamics of DR transformer inductance, DC smoothing reactance and HVDC cable is thus depicted by (13) and (17).

The small signal model of the DR filter, the offshore wind farm (including WT, WT $L C$ filter, WT transformer and AC cable) and the validation of the developed small signal model are presented in Appendix. B.

\section{ANALYSIS OF THE WT $Q-F$ CONTROL}

With the onshore DC voltage $V_{d c i}$ controlled at rated value by the MMC, the DR-HVDC transmitted active power $P_{d r}$ is mainly determined by the offshore PCC voltage magnitude $E$. When $E$ increases, the HVDC transmitted active power $P_{d r}$ increases and vice versa. Such interaction provides the scientific base for the WT $P-V$ control design $[8,12]$.

On the other hand, although $Q-f$ droop control is used in [1216] for WT reactive power sharing, the justification for its use and the design procedure of the $Q-f$ droop gain $k_{q}$ have not been clarified and properly understood. Besides, the impedance between individual WT converter and the offshore PCC is predominately inductive, as the $\mathrm{AC}$ cable resistance and capacitance are much less than the combined inductances of WT converter line reactor and WT transformer leakage inductance. Thus, the $i^{\text {th }}(i=1,2 \ldots, 40)$ WT active power transmitted to the offshore PCC is mainly determined by the phase difference between the $i^{\text {th }}$ WT converter filter voltage phase angle $\theta_{i}$ and that of the offshore PCC $\theta_{e}$, while the WT 
reactive power $Q_{w t i}$ is mainly determined by the WT filter voltage $V_{f i}$, as depicted by (18) and (19) [21]:

$$
\begin{gathered}
P_{w t i}=\frac{E V_{f i} \sin \left(\theta_{i}-\theta_{e}\right)}{X_{i}} \\
Q_{w t i}=\frac{\left(V_{f i}-E \cos \left(\theta_{i}-\theta_{e}\right)\right) V_{f i}}{X_{i}}
\end{gathered}
$$

where $X_{i}$ is the equivalent inductance between the WT filter and offshore PCC. How active and reactive power interact and the WT phase angle changes during WT active power variation have not been analyzed.

In this section, stability analysis is carried out for the design of the $Q-f$ droop control parameter $k_{q}$ based on the developed small signal model. Then time domain analysis is conducted to reveal the operation mechanism of WT $Q-f$ droop control and interaction between active and reactive power during WT active power change.

\section{A. Stability analysis of the WT Q-f droop control}

Fig. 3 shows the movements of the most-affected poles when $k_{q}$ increases from 0.001 to $18.001 \mathrm{rad} /(\mathrm{sMVAr})$ by the step of 2 $\mathrm{rad} /(\mathrm{sMVAr})$. As can be seen, the DR-HVDC connected offshore wind farm remains stable until $k_{q}$ increases from 16.001 to $18.001 \mathrm{rad} /(\mathrm{sMVAr})$.

Fig. 4 shows the PSCAD simulation results when $k_{q}$ increases from 16.001 to $18.001 \mathrm{rad} . /(\mathrm{s} \cdot \mathrm{MVAr})$ at $0.3 \mathrm{~s}$ and returns to $16.001 \mathrm{rad} . /(\mathrm{s} \cdot \mathrm{MVAr})$ at $0.4 \mathrm{~s}$. As can be seen, the system is unstable when $k_{q}$ is $18.001 \mathrm{rad} . /(\mathrm{s} \cdot \mathrm{MVAr})$ but becomes stable when $k_{q}$ restores to $16.001 \mathrm{rad} . /\left(\mathrm{s}^{\cdot} \mathrm{MVAr}\right)$, which is in good agreement with the root locus analysis in Fig. 3.

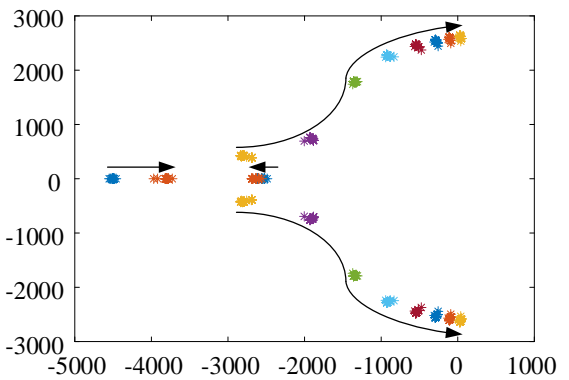

Fig. 3 Root locus when $k_{q}$ increases from 0.001 to $18.001 \mathrm{rad} /(\mathrm{sMVAr})$ by step of $2 \mathrm{rad} /(\mathrm{sMVAr})$.
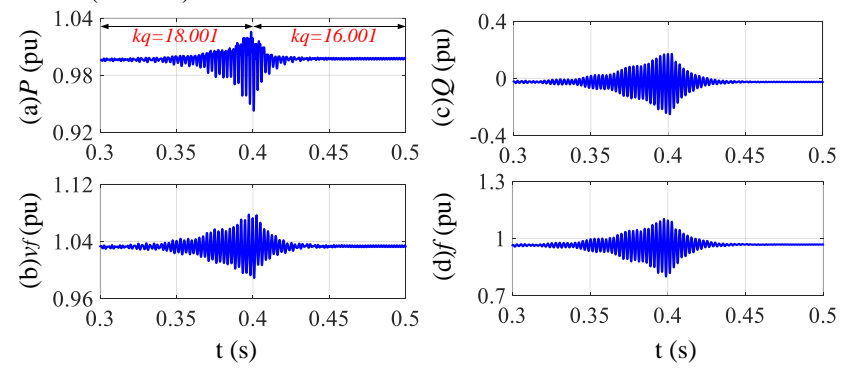

Fig. 4 PSCAD results for WT5 when $k_{q}$ steps from 18.001 to 16.001 $\mathrm{rad} /(\mathrm{sMVAr}$ ) at $0.4 \mathrm{~s}$ : (a) active power; (b) AC voltage; (c) reactive power; (d) frequency.

\section{B. Time domain analysis of the WT Q-f droop control}

As discussed, when $P-V$ and $Q-f$ control is applied for each WT converter, how active and reactive power interact and the WT phase angle changes during WT active power variation have not been analyzed. In this subsection, time-domain simulation results in PSCAD/EMTDC are presented in Fig. 5, to clarify the operation mechanism of the adopted $P-V$ and $Q-f$ control scheme.
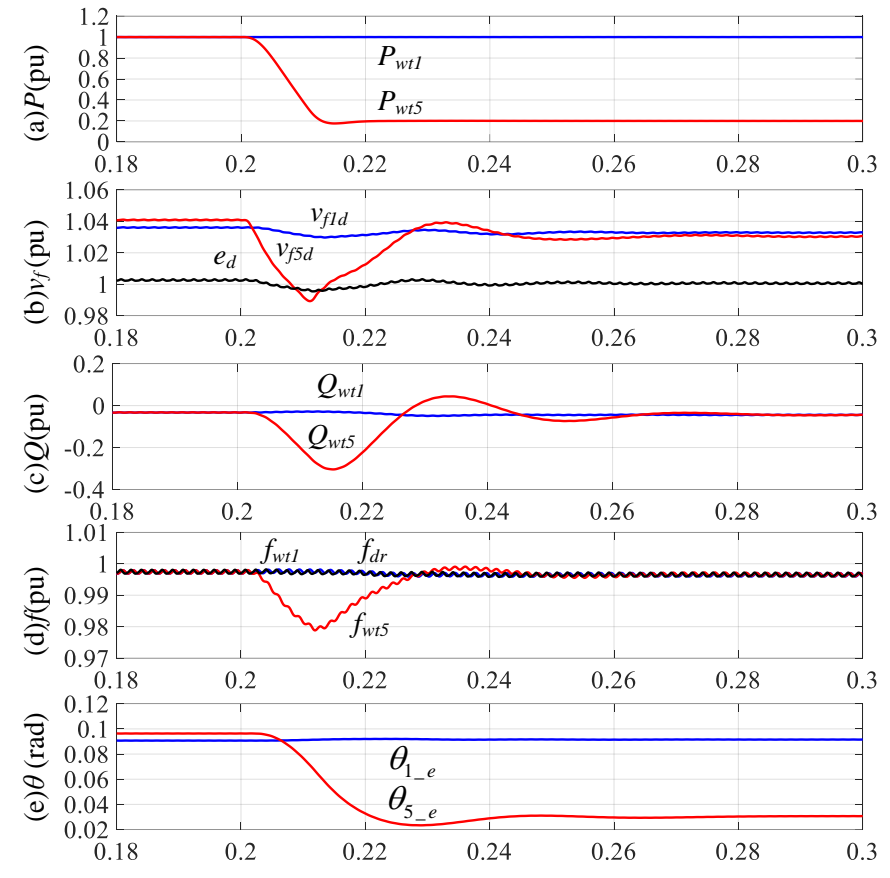

Fig. 5 Performance of the system when WT5 active power order changes: (a) WT1 and WT5 active power; (b) WT1, WT5 and PCC $d$-axis voltage; (c) WT1 and WT5 reactive power; (d) WT1, WT5 and PCC frequency; (e) phase difference between WT1 and PCC $\left(\theta_{1-\mathrm{e}}\right)$, WT5 and PCC $\left(\theta_{5-\mathrm{e}}\right)$.

During 0.2 to $0.21 \mathrm{~s}$, one of the 40 WTs (WT5 in string 2 as shown in Fig. 1) ramps down its active power reference from 1 to $0.2 \mathrm{pu}$. Due to the action of $P$ - $V$ controller, WT5 AC voltage $v_{f d 5}$ decreases from 1.04 to 0.99 pu, as shown in Fig. 5 (b). The drop of $v_{f d s}$ leads to the decrease of the capacitive reactive power of WT5 $Q_{w t 5}$ from -0.03 to -0.31 pu at $0.21 \mathrm{~s}$, as shown in Fig. 5 (c).

Due to the action of $Q-f$ droop controller, the WT5 reactive power decrease results in the reduction of WT5 frequency $f_{w t 5}$ from 0.998 to 0.978 pu during $0.2-0.21 \mathrm{~s}$. Meanwhile, the PCC frequency $f_{d r}$ and WT1 frequency $f_{w t l}$ decrease slightly during this period, as shown in Fig. 5 (d). Consequently, the phase difference $\theta_{5_{-} e}$ between WT5 output voltage vector and PCC voltage vector decreases from $0.096 \mathrm{rad}$. $\left(5.44^{\circ}\right)$ to $0.07 \mathrm{rad}$. $\left(4.01^{\circ}\right)$ at $0.21 \mathrm{~s}$, as shown in Fig. 5 (e).

After $0.21 \mathrm{~s}$, the phase difference $\theta_{5_{-} e}$ continues to decrease from $0.07 \mathrm{rad} .\left(4.01^{\circ}\right)$ and eventually settles at $0.03 \mathrm{rad} .\left(1.72^{\circ}\right)$, as shown in Fig. 5 (e). With the continuous decrease of phase angle after $0.21 \mathrm{~s}$, the AC voltage $v_{f d s}$ starts to increase from 0.99 to $1.03 \mathrm{pu}$, so as to ensure the transmitted active power of WT5 $P_{w t 5}$ maintains at 0.2 pu, as can be seen in Fig. 5 (b) and (a). This WT AC voltage $v_{f d s}$ recovery results in the increase of WT reactive power $Q_{w t 5}$ from -0.31 to $-0.032 \mathrm{pu}$ and the increase of the WT frequency $f_{w t 5}$ from 0.978 to $0.997 \mathrm{pu}$, as shown in Fig. 5 (c) and (d).

As seen from the simulation results in Fig. 5, it can be concluded that

- Change of active power transmission from an individual 
WT to the offshore network is mainly influenced by the variation of phase angle between the WT AC output and the PCC as in a conventional power network, while the transmitted DR-HVDC active power depends on the variation of wind farm PCC AC voltage magnitude.

- The variation of WT phase angle is achieved through the combined interactions among WT $P-V$ control, inductive impedance between the WT and offshore PCC, and $Q-f$ control, as illustrated in Fig. 6.

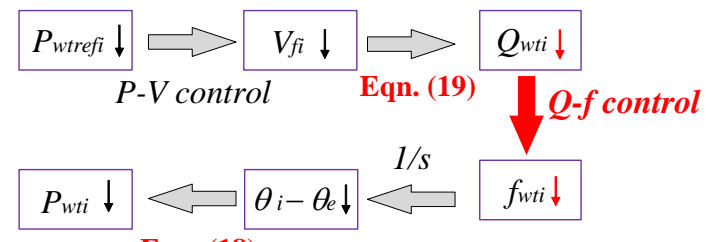

Eqn. (18)

Fig. 6 WT active power change mechanism with the $P-V$ and $Q-f$ control.

V. Proposed ANGLE FEEDFORWARd CONTROL STRATEGY OF WTS CONNECTED WITH DR-HVDC SYSTEM

\section{A. Interaction between WT active power and reactive power}

As can be seen in Fig. 5, the use of $P-V$ and $Q-f$ control and the inductive impedance between the WT converter and offshore PCC result in the strong interaction between the WT active and reactive power. During the decrease of a WT active power, its reactive power also decreases initially to change the WT output phase angle.

In addition to the time-domain responses, the interaction between WT active power and reactive power is also analysed based on the frequency-domain results from the developed small-signal model. The Bode response from WT5 active power reference to reactive power in shown in Fig. 7, which indicates the degree of WT reactive power disturbance caused by WT active power change.

The peak gain of $-2.5 \mathrm{~dB}$ occurs at around $28 \mathrm{~Hz}$, which is in accordance with the reactive power oscillation frequency during active power change as demonstrated in Fig. 5.

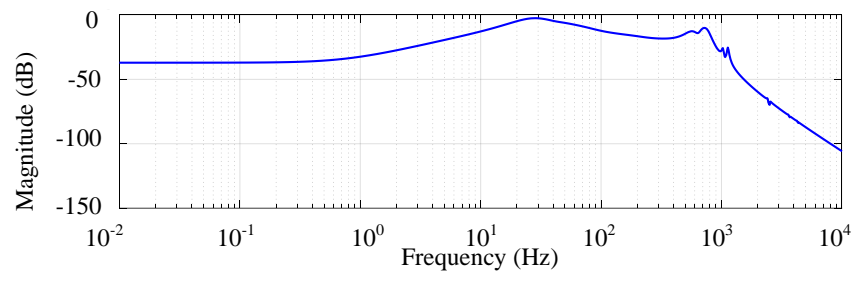

Fig. 7 Bode response from active power reference to reactive power.

\section{B. Proposed angle feedforward control}

To reduce the interaction between WT active power and reactive power, an angle feedforward control is proposed in this subsection.

During the power change of one single WT, the variation of offshore PCC voltage $E$ is much less than that of converter output voltage $V_{c}$ (as shown in Fig. 5), and thus, $E$ is considered as being constant here. Thus, WT active power and reactive power variation is expressed as

$$
\triangle P_{w t c}=\frac{E_{0} V_{c 0} \cos \theta_{c o}}{X} \Delta \theta_{c}+\frac{E_{0} \sin \theta_{c 0}}{X} \Delta V_{c} .
$$

$$
\Delta Q_{w t c}=\frac{E_{0} \sin \theta_{c 0} V_{c 0}}{X} \Delta \theta_{c}+\frac{2 V_{c 0}-E_{0} \cos \theta_{c 0}}{X} \Delta V_{c}
$$

As $E_{0} V_{c 0} \cos \theta_{c o} / X \gg E_{0} \sin \theta_{c 0} / X$ for a typical small phase shift $\theta_{c o}$, phase angle variation at each WT terminal has a much higher impact on WT active power change than the WT AC voltage variation.

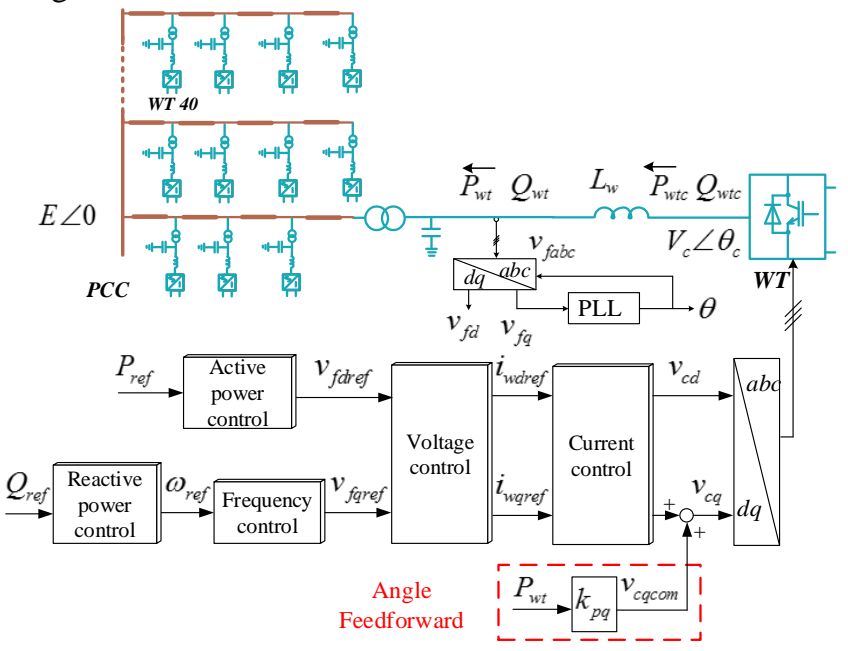

Fig. 8 Proposed WT angle feedforward control scheme.

If WT phase angle can be regulated faster during the active power variation, WT terminal AC voltage fluctuation can be effectively reduced, as depicted by (20). As a result, WT reactive power dynamics during the transient can be improved, as seen in (21). Based on these observations, an additional angle feedforward control as shown in Fig. 8 is proposed to reduce the interaction between WT active and reactive power. The angle feedforward control takes the WT active power as the input and regulates the $q$-axis component of the converter output voltage reference $v_{c q}$ (to directly affect the phase angle), which is expresses as

$$
v_{\text {cqcom }}=k_{p q} P_{w t}
$$

where $k_{p q}$ is the gain of the angle feedforward control. When the WT generated active power increases, the WT output phase angle will quickly increase with the proposed angle feedforward control, leading to reduced AC voltage and reactive power fluctuation. Similarly, when the WT generated active power decreases, the WT output phase angle will quickly decrease to reduce the variation of $\mathrm{AC}$ voltage and reactive power. The coupling between the active and reactive power is thus reduced.

\section{Comparison between the proposed control and conventional control}

Fig. 9 shows the gain of the transfer function from WT active power reference to reactive power with different gains of the angle feedforward control $\left(k_{p q}\right)$. As can be seen, the peak gain (at around $28 \mathrm{~Hz}$ ) is effectively decreased from $-2.5 \mathrm{~dB}$ with conventional control (i.e. $k_{p q}=0$ ) to $-15.5 \mathrm{~dB}$ with the proposed control when $k_{p q}=0.0015 \mathrm{kV} / \mathrm{MW}$, indicating reduced interaction between $\mathrm{WT}$ active and reactive power. This demonstrates that WT active power change causes less disturbance on the reactive power with the proposed control. However, when $k_{p q}$ is further increased from 0.0015 to 0.003 
Electrical and Electronic Engineering Copyright. The copy of record is available at IEEE Xplore Digital Library.

$\mathrm{kV} / \mathrm{MW}$, the Bode plot peak gain starts to increase, indicating the increased interaction between WT active power and reactive power. Therefore, $k_{p q}$ is set at $0.0015 \mathrm{kV} / \mathrm{MW}$ in this paper.

In low frequency range $(f<5 \mathrm{~Hz})$, the proposed angle feedforward control exhibits the same responses as those of conventional control, demonstrating that the steady state active and reactive power are not affected by the additional control loop.

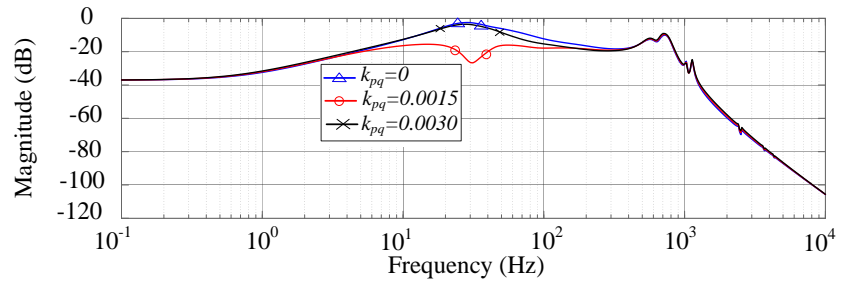

Fig. 9 Bode response from power reference to reactive power.

The WT responses with the proposed angle feedforward control are compared to those with the conventional method [12] in PSCAD/EMTDC time-domain simulation, as shown in Fig. 10. In steady state (before $0.2 \mathrm{~s}$ ), both control methods operate satisfactorily at the same operation point.

From $0.2 \mathrm{~s}$ to $0.21 \mathrm{~s}$, the active power order of WT5 in string 2 (shown in Fig. 1) decreases from 1 to $0.2 \mathrm{pu}$. As shown in Figs. 10 (b) and (c), the proposed angle feedforward control with $k_{p q}$ at $0.0015 \mathrm{kV} / \mathrm{MW}$ leads to lower WT AC voltage variation and significant reduction of reactive power oscillation during the active power change when compared to the conventional control (i.e. $k_{p q}=0$ ). Also, the system with $k_{p q}=0.0015 \mathrm{kV} / \mathrm{MW}$ exhibits better overall performance compared to that with $k_{p q}=0.003 \mathrm{kV} / \mathrm{MW}$, which is in agreement with the frequency domain analysis in Fig. 9.
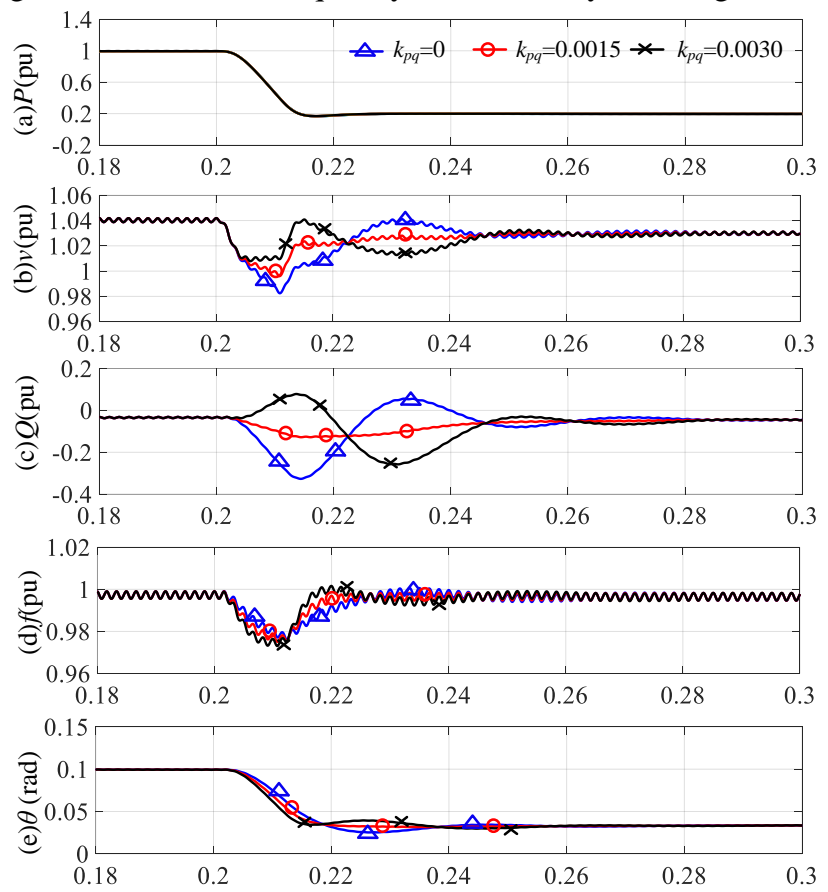

Fig. 10 System performance when WT5 active power order changes with the proposed control and conventional control (i.e. $k_{p q}$ increases from 0 to 0.003 kV/MW): (a) WT5 active power; (b) WT5 AC voltage; (c) WT5 reactive power;

(d) WT5 frequency; (e) phase difference between WT5 and PCC $\left(\theta_{5-\text { e }}\right)$.

From the Nyquist plot of the open loop active power control shown in Fig. 11, the phase margin largely remains at $75^{\circ}$ with the variation of $k_{q p}$ from 0 to $0.0030 \mathrm{kV} / \mathrm{MW}$. This indicates that, with the brought benefits as demonstrated in Fig. 10, the proposed angle feedforward control does not have negative influence on system stability.

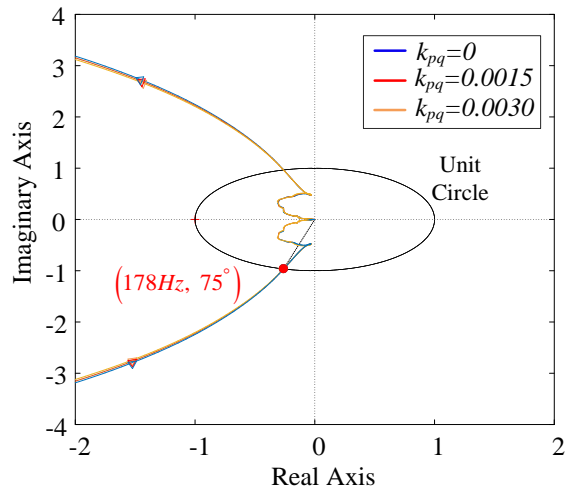

Fig. 11 Stability margin of the WT active power control when the angle feedforward control parameter changes from 0 to $0.003 \mathrm{kV} / \mathrm{MW}$.

\section{Validation of the angle feedforward control at different operation points}

The proposed control is further validated at different operation points and high power setpoint changes.

In this scenario, the active power of all the WTs are initially at $0.2 \mathrm{pu}$ and the active power order of WT5 is ramped up to 1 pu within the period of 0.2 to $0.21 \mathrm{~s}$. As can be seen in Fig. 12 (b) and (c), with the proposed angle feedforward control, WT reactive power oscillation is significantly reduced during the active power change compared to that without the proposed control. Similar to Fig. 11, the system stability phase margin is not significantly affected with the angle feedforward control in this case and thus is not repeated here.
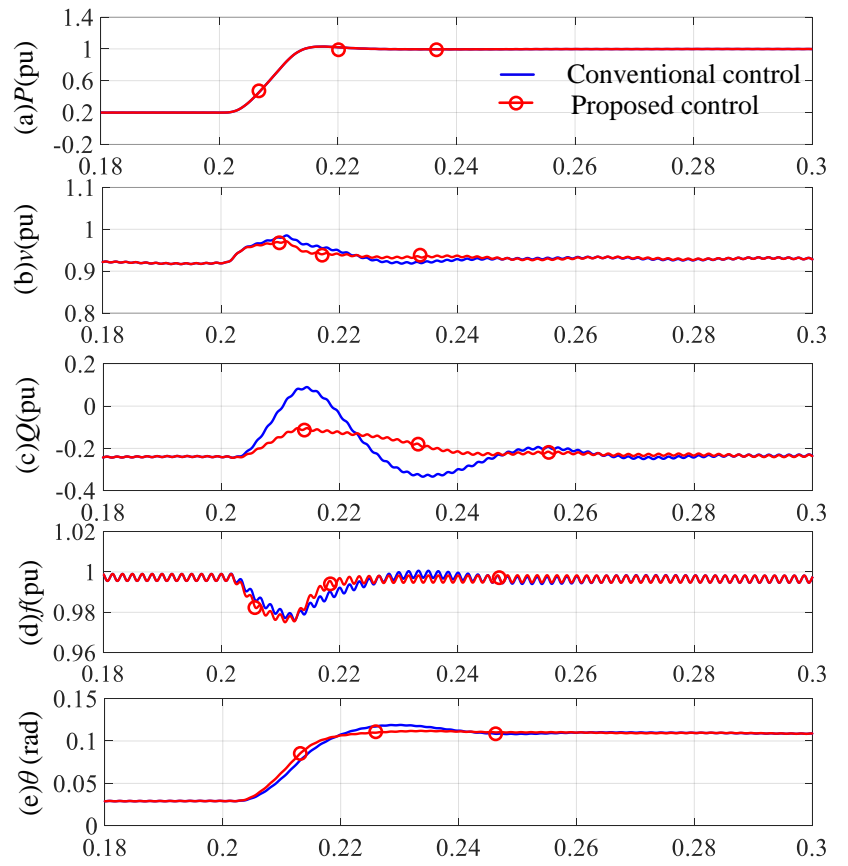

Fig. 12 System performance with WT5 active power change from 0.2 to 1 pu: (a) WT5 active power; (b) WT5 AC voltage; (c) WT5 reactive power; (d) WT5 frequency; (e) phase difference between WT5 and PCC $\left(\theta_{5-\mathrm{e}}\right)$.

The robustness of the proposed angle feedforward control is further validated during higher power setpoint changes. 
Initially, all the WTs generate rated active power. At $0.2 \mathrm{~s}$, WT1 quickly decreases its active power from rated power to $0.1 \mathrm{pu}$, whereas the other 39 WTs reduce their power from 1 pu to 0.8 $\mathrm{pu}$ in the meantime. The performances of WT1 in this scenario are presented in Fig. 13.
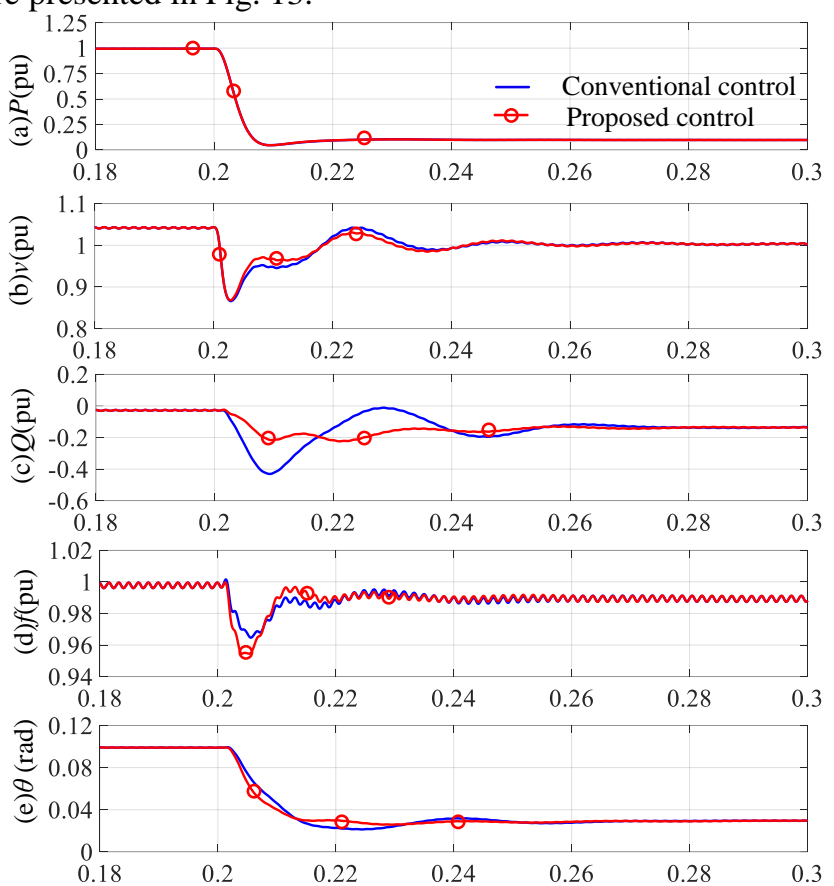

Fig. 13 System performance during WT1 high power setpoint change (from 1 to $0.1 \mathrm{pu}$ ): (a) WT1 active power; (b) WT1 AC voltage; (c) WT1 reactive power; (d) WT1 frequency; (e) phase difference between WT1 and PCC $\left(\theta_{1-e}\right)$.

As wind speed constantly varies across the whole wind farm, all the WT output active powers also vary accordingly. With the proposed angle feedforward control, reactive power oscillations for all the WTs are significantly reduced during normal active power variation. Thus, WT grid current oscillation is reduced leading to higher converter efficiency and potential longer lifespan.

\section{CONCLUSION}

A small-signal state-space model of WTs connected with DR-HVDC systems is developed. Using the developed smallsignal model, the design of $Q-f$ control is studied, and the interaction between active and reactive power with $P-V$ and $Q$ $f$ control is investigated. Moreover, the detailed mechanism and process on WT active power change with the $P-V$ and $Q-f$ control is clarified. An angle feedforward control is proposed to reduce the coupling between WT active and reactive power. Frequency-domain Bode responses and time-domain simulations using PSCAD/EMTDC verify that the proposed control effectively alleviates the variations of the offshore AC voltage and reactive power during active power change.

\section{APPENDIX. A}

Table I

Parameters of the Tested DR-HVDC System

\begin{tabular}{l|c|c}
\hline Components & Parameters & Values \\
\hline & Converter reactance & $0.15 \mathrm{pu}$ \\
\hline
\end{tabular}

\begin{tabular}{|c|c|c|}
\hline \multirow{2}{*}{$\begin{array}{c}\text { WT } \\
\text { converters }\end{array}$} & Filter capacitor & $0.1 \mathrm{pu}$ \\
\hline & $\begin{array}{c}\text { Transformer } \\
\text { leakage inductance }\end{array}$ & $\begin{array}{c}0.69 \mathrm{kV} / 66 \mathrm{kV} \\
0.08 \mathrm{pu}\end{array}$ \\
\hline AC cable & $R_{a c}, L_{a c}, C_{a c}$ & $0.6 \Omega, 2 \mathrm{mH}, 2 \times 0.672 \mu \mathrm{F}$ \\
\hline \multirow{2}{*}{ DR filter } & Low frequency filter & $\begin{array}{c}116.98 \mu \mathrm{F} ; 1300 \mu \mathrm{F} ; \\
7.8 \mathrm{mH} ; 1.70 \Omega ; 14.97 \Omega\end{array}$ \\
\hline & High frequency filter & $116.98 \mu \mathrm{F} ; 0.78 \mathrm{mH} ; 4.76 \Omega$ \\
\hline \multirow{3}{*}{ 12-pulse DR } & $\begin{array}{c}\text { Transformer } \\
\text { leakage inductance }\end{array}$ & $\begin{array}{c}66 \mathrm{kV} / 261.8 \mathrm{kV} / 261.8 \mathrm{kV} \\
0.18 \mathrm{pu}\end{array}$ \\
\hline & Power, DC voltage & $1000 \mathrm{MW} ; \pm 320 \mathrm{kV}$ \\
\hline & DC smoothing reactance & $0.24 \mathrm{H}$ \\
\hline DC cables $[8]$ & $R_{d c}, L_{d c}, C_{d c}$ & $1.25 \Omega ; 0.06 \mathrm{H} ; 26 \mu \mathrm{F}$ \\
\hline \multirow{4}{*}{$\begin{array}{l}\text { Control } \\
\text { parameters }\end{array}$} & $\begin{array}{l}\text { Current control: } k_{i p ;} k_{i i ;} \\
\text { Voltage control: } k_{v p ;} k_{v i}\end{array}$ & $\begin{array}{c}0.0057 \Omega ; 0.909 \Omega . / \mathrm{s} ; \\
4.175 \Omega^{-1} ; 278.34 \Omega^{-1} \mathrm{~s}^{-1}\end{array}$ \\
\hline & $\begin{array}{c}P L L: k_{l p ;} k_{l i ;} \\
P \text { control: } k_{p p ;} k_{p i}\end{array}$ & $\begin{array}{c}448.2 \mathrm{rad} /(\mathrm{sv}) ; 7052 \mathrm{rad} /\left(\mathrm{s}^{2} \mathrm{v}\right) ; \\
0.5 \mathrm{kV} / \mathrm{MW} ; 1 \mathrm{kV} /(\mathrm{sMW})\end{array}$ \\
\hline & $\begin{array}{c}f \text { control: } k_{f ;} \\
Q-f \text { droop control: } k_{q}\end{array}$ & $\begin{array}{l}0.1(\mathrm{skV}) / \mathrm{rad} \\
1 \mathrm{rad} /(\mathrm{sMVAr})\end{array}$ \\
\hline & $\begin{array}{l}\text { Angle feedforward } \\
\text { control: } k_{p q}\end{array}$ & $0.0015 \mathrm{kV} / \mathrm{MW}$ \\
\hline
\end{tabular}

\section{APPENDIX. B}

\section{A. Small-signal model of diode rectifier filter}

The diode rectifier filter shown in Fig. 1 is represented as

$$
\begin{aligned}
& C_{1} d v_{1} / d t=-\left(R_{2}+R_{3}\right) v_{1} / R_{2} R_{3}+v_{2} / R_{2}+v_{4} / R_{3}-j \omega_{d r} C_{1} v_{1} \\
& -i_{1}-i_{2}+i_{\text {casumd }}-i_{d r} \\
& C_{2} d v_{2} / d t=v_{1} / R_{2}-v_{2} / R_{2}+i_{1}-j \omega_{d r} C_{2} v_{2} \\
& C_{3} d v_{3} / d t=i_{1}-j \omega_{d r} C_{3} v_{3} \\
& C_{4} d v_{4} / d t=i_{2}+v_{1} / R_{3}-v_{4} / R_{3}-j \omega_{d r} C_{4} v_{4} \\
& L_{1} d i_{1} / d t=v_{1}-v_{2}-v_{3}-R i_{1}-j \omega_{d r} L_{1} i_{1} \\
& L_{2} d i_{2} / d t=v_{1}-v_{4}-j \omega_{d r} L_{2} i_{2}
\end{aligned}
$$

Linearizing at the operating point, the small-signal model in the $d q$ reference is expressed as

$$
\begin{aligned}
& {\left[\begin{array}{cccccc}
\Delta \dot{v}_{1 d q} & \Delta \dot{v_{2 d q}} & \Delta \dot{v_{3 d q}} & \Delta \dot{v_{4 d q}} & \Delta \dot{i_{1 d q}} & \Delta \dot{i_{2 d q}}
\end{array}\right]^{T}} \\
& =A_{d r f}\left[\begin{array}{llllll}
\Delta v_{1 d q} & \Delta v_{2 d q} & \Delta v_{3 d q} & \Delta v_{4 d q} & \Delta i_{1 d q} & \Delta i_{2 d q}
\end{array}\right]^{T} \\
& +B_{d r f}\left[\begin{array}{llll}
\Delta \omega_{d r} & \Delta i_{\text {casumdq }} & \Delta i_{d r d q}
\end{array}\right]^{T}
\end{aligned}
$$

where

$$
A_{d r f}=\left[\begin{array}{cccccccccccc}
-\frac{R_{2}+R_{3}}{R_{2} R_{3} C_{1}} & \omega_{d r 0} & \frac{1}{R_{2} C_{1}} & 0 & 0 & 0 & \frac{1}{R_{3} C_{1}} & 0 & -\frac{1}{C_{1}} & 0 & \frac{1}{C_{1}} & 0 \\
-\omega_{d r 0} & -\frac{R_{2}+R_{3}}{R_{2} R_{3} C_{1}} & 0 & \frac{1}{R_{2} C_{1}} & 0 & 0 & 0 & \frac{1}{R_{3} C_{1}} & 0 & -\frac{1}{C_{1}} & 0 & \frac{1}{C_{1}} \\
\frac{1}{R_{2} C_{2}} & 0 & -\frac{1}{R_{2} C_{2}} & \omega_{d r 0} & 0 & 0 & 0 & 0 & \frac{1}{C_{2}} & 0 & 0 & 0 \\
0 & \frac{1}{R_{2} C_{2}} & -\omega_{d r 0} & -\frac{1}{R_{2} C_{2}} & 0 & 0 & 0 & 0 & 0 & \frac{1}{C_{2}} & 0 & 0 \\
0 & 0 & 0 & 0 & 0 & -\omega_{d r 0} & 0 & 0 & \frac{1}{C_{3}} & 0 & 0 & 0 \\
0 & 0 & 0 & 0 & \omega_{d r 0} & 0 & 0 & 0 & 0 & \frac{1}{C_{3}} & 0 & 0 \\
\frac{1}{R_{3} C_{4}} & 0 & 0 & 0 & 0 & 0 & -\frac{1}{R_{3} C_{4}} & \omega_{d r 0} & 0 & 0 & \frac{1}{C_{4}} & 0 \\
0 & \frac{1}{R_{3} C_{4}} & 0 & 0 & 0 & 0 & \omega_{d r 0} & -\frac{1}{R_{3} C_{4}} & 0 & 0 & 0 & \frac{1}{C_{4}} \\
\frac{1}{L_{1}} & 0 & -\frac{1}{L_{1}} & 0 & -\frac{1}{L_{1}} & 0 & 0 & 0 & -\frac{R_{1}}{L_{1}} & \omega_{d r 0} & 0 & 0 \\
0 & \frac{1}{L_{1}} & 0 & -\frac{1}{L_{1}} & 0 & -\frac{1}{L_{1}} & 0 & 0 & -\omega_{d r 0} & -\frac{R_{1}}{L_{1}} & 0 & 0 \\
\frac{1}{L_{2}} & 0 & 0 & 0 & 0 & 0 & -\frac{1}{L_{2}} & 0 & 0 & 0 & 0 & \omega_{d r 0} \\
0 & \frac{1}{L_{2}} & 0 & 0 & 0 & 0 & 0 & -\frac{1}{L_{2}} & 0 & 0 & -\omega_{d r 0} & 0
\end{array}\right]
$$




$B_{d r f}=\left[\begin{array}{cccccccccccc}v_{1 q 0} & -v_{1 d 0} & v_{2 q 0} & -v_{2 d 0} & v_{3 q 0} & -v_{3 d 0} & v_{4 q 0} & -v_{4 d 0} & i_{1 q 0} & -i_{1 d 0} & i_{2 q 0} & -i_{2 d 0} \\ 1 / C_{1} & 0 & 0 & 0 & 0 & 0 & 0 & 0 & 0 & 0 & 0 & 0 \\ 0 & 1 / C_{1} & 0 & 0 & 0 & 0 & 0 & 0 & 0 & 0 & 0 & 0 \\ -1 / C_{1} & 0 & 0 & 0 & 0 & 0 & 0 & 0 & 0 & 0 & 0 & 0 \\ 0 & -1 / C_{1} & 0 & 0 & 0 & 0 & 0 & 0 & 0 & 0 & 0 & 0\end{array}\right]^{T}$

B. Small-signal model of the WT, output LC filter and transformer inductance

The WT is modelled by its line-side converter as the generator side converter and generator have no significant participation on offshore network stability [22]-[23]. Pulse width modulation (PWM) of the line-side converter is considered and modelled as a first-order delay with its time constant at half of the PWM switching period. The WT output $L C$ filter and transformer inductance, as shown in Fig. 2 is represented as

$$
\begin{aligned}
& L_{w} d i_{w} / d t=-j \omega L_{w} i_{w}+v_{c}-v_{f}-R_{w} i_{w} \\
& C_{f} d v_{f} / d t=-j \omega C_{f} v_{f}+i_{w}-i_{s} \\
& L_{s} d i_{s} / d t=-j \omega L_{s} i_{s}+v_{f}-v_{c a} / T_{w t}
\end{aligned} .
$$

The corresponding small-signal state space form of the $L C$ filter and transformer reactance in the $d q$ reference is expressed as

$$
\left[\begin{array}{c}
\dot{i_{w d q}} \\
\dot{v_{f d q}} \\
\dot{i_{s d q}}
\end{array}\right]=A_{c o n}\left[\begin{array}{c}
\Delta i_{w d q} \\
\Delta v_{f d q} \\
\Delta i_{s d q}
\end{array}\right]+B_{c o n}\left[\begin{array}{c}
\Delta \omega \\
\Delta v_{c d q} \\
\Delta v_{c a d q}
\end{array}\right]
$$

where

$$
\begin{gathered}
A_{c o n}=\left[\begin{array}{cccccc}
-R_{w} / L_{w} & \omega_{0} & -1 / L_{w} & 0 & 0 & 0 \\
-\omega_{0} & -R_{w} / L_{w} & 0 & -1 / L_{w} & 0 & 0 \\
1 / C_{f} & 0 & 0 & \omega_{0} & -1 / C_{f} & 0 \\
0 & 1 / C_{f} & -\omega_{0} & 0 & 0 & -1 / C_{f} \\
0 & 0 & 1 / L_{s} & 0 & 0 & \omega_{0} \\
0 & 0 & 0 & 1 / L_{s} & -\omega_{0} & 0
\end{array}\right] \\
B_{c o n}=\left[\begin{array}{cccccc}
i_{w q 0} & 1 / L_{w} & 0 & 0 & 0 \\
-i_{w d 0} & 0 & 1 / L_{w} & 0 & 0 \\
v_{f q 0} & 0 & 0 & 0 & 0 \\
-v_{f d 0} & 0 & 0 & 0 & 0 \\
i_{s q 0} & 0 & 0 & -1 / L_{s} T_{w t} & 0 \\
-i_{s d 0} & 0 & 0 & 0 & -1 / L_{s} T_{w t}
\end{array}\right]
\end{gathered}
$$

\section{Small-signal model of AC cable}

AC cable is modelled as one $R-L-C \pi$ section due to its relative short length. When the $\pi$ sections of the AC cables are connected in series, it is equivalent to use $\Gamma$ sections as two parallel capacitors from the two cables at a same point can be regarded as one capacitor with twice the original value, as shown in Fig. 2. The AC cable is represented as

$$
\begin{aligned}
& C_{c a} d v_{c a} / d t=-j \omega C_{c a} v_{c a}+i_{s} / T_{w t}-i_{c a} \\
& L_{c a} d i_{c a} / d t=-j \omega L_{c a} i_{c a}+v_{c a}-v_{c a 2_{-} 1}-R_{c a} i_{c a}
\end{aligned} .
$$

Linearizing at the operating point, the small-signal model of AC cable in the $d q$ reference is expressed as

$$
\begin{aligned}
& {\left[\begin{array}{c}
\dot{\Delta v_{c a d q}} \\
\dot{\bullet} \\
\Delta i_{c a d q}
\end{array}\right]=\left[\begin{array}{cccc}
0 & \omega_{0} & -1 / C_{c a} & 0 \\
-\omega_{0} & 0 & 0 & -1 / C_{c a} \\
1 / L_{c a} & 0 & -R_{c a} / L_{c a} & \omega_{0} \\
0 & 1 / L_{c a} & -\omega_{0} & -R_{c a} / L_{c a}
\end{array}\right]\left[\begin{array}{c}
\Delta v_{c a d q} \\
\Delta i_{c a d q}
\end{array}\right]} \\
& +\left[\begin{array}{ccccc}
v_{c a q} 0 & 1 / C_{c a} T_{w t} & 0 & 0 & 0 \\
-v_{c a d} 0 & 0 & 1 / C_{c a} T_{w t} & 0 & 0 \\
i_{c a q} 0 & 0 & 0 & -1 / L_{c} a & 0 \\
-i_{c a d} 0 & 0 & 0 & 0 & -1 / L_{c a}
\end{array}\right]\left[\begin{array}{c}
\Delta \omega \\
\Delta i_{s d q} \\
\Delta v_{c a 2_{2} 1 d q}
\end{array}\right]
\end{aligned}
$$

\section{Complete small-signal model of the offshore wind farm}

Due to the distributed control of the WT line-side converter, the small-signal model of each WT converter and control is based on its own rotating $d q$ reference [12], as shown in Fig. 14. When two WT converters are connected to a common point, it is necessary to transform the individual rotating reference to a common reference for stability analysis [24].

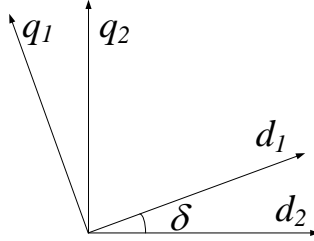

Fig. 14 Diagram of small-signal reference frame transformation

As shown in Fig. 2, the transformer of WT2 is directly connected with AC cable 1 . The current injected into AC cable $2 i_{\text {sum } 2}$ is the total current from both WT2 transformer $i_{s 2} / T_{w t}$ and AC cable $1 i_{c a}$, which should be based on the same rotating reference. Thus, the current of AC cable1 $i_{c a d q}$ in $d_{1} q_{1}$ reference frame is transformed to that based on $d_{2} q_{2}$ reference $i_{c a 1 \_2 d q}$, which is expressed as

$$
\begin{aligned}
& i_{c a 1_{\_} 2 d}=i_{c a d} \cos \delta-i_{c a q} \sin \delta \\
& i_{c a 1_{-} 2 q}=i_{c a q} \cos \delta+i_{c a d} \sin \delta
\end{aligned} .
$$

Linearizing (33) at the operating point, the expression of the current deviation can be obtained

$$
\begin{aligned}
& {\left[\begin{array}{l}
\Delta i_{c a 1_{\_} 2 d} \\
\Delta i_{c a 1_{1} 2 q}
\end{array}\right]=\left[\begin{array}{cc}
\cos \delta_{0} & -\sin \delta_{0} \\
\sin \delta_{0} & \cos \delta_{0}
\end{array}\right]\left[\begin{array}{l}
\Delta i_{c a d} \\
\Delta i_{c a q}
\end{array}\right] .} \\
& +\left[\begin{array}{l}
-i_{c a d 0} \sin \delta_{0}-i_{c a q 0} \cos \delta_{0} \\
-i_{c a q 0} \sin \delta_{0}+i_{c a d 0} \cos \delta_{0}
\end{array}\right][\Delta \delta]
\end{aligned}
$$

On the other hand, as shown in (32), the input of the AC cable 1 small-signal model is the voltage of the connection point $v_{c a 2}$, which is expressed in the $d_{2} q_{2}$ reference frame. The voltage needs to be converted to that based on $d_{l} q_{l}$ reference $v_{c a 2_{-} 1 d q}$ using the reversed transformation, expressed as

$$
\begin{aligned}
& {\left[\begin{array}{c}
\Delta v_{c a 2_{2} 1 d} \\
\Delta v_{c a 2_{2} 1 q}
\end{array}\right]=\left[\begin{array}{cc}
\cos \delta_{0} & \sin \delta_{0} \\
-\sin \delta_{0} & \cos \delta_{0}
\end{array}\right]\left[\begin{array}{l}
\Delta v_{c a 2 d} \\
\Delta v_{c a 2 q}
\end{array}\right] \text {. }} \\
& +\left[\begin{array}{l}
-v_{c a 2 d 0} \sin \delta_{0}+v_{c a 2 q 0} \cos \delta_{0} \\
-v_{c a 2 q 0} \sin \delta_{0}-v_{c a 2 d 0} \cos \delta_{0}
\end{array}\right][\Delta \delta]
\end{aligned}
$$

Fig. 15 shows the complete small-signal model of $40 \mathrm{WT}$ line-side converters connected with DR-HVDC. 


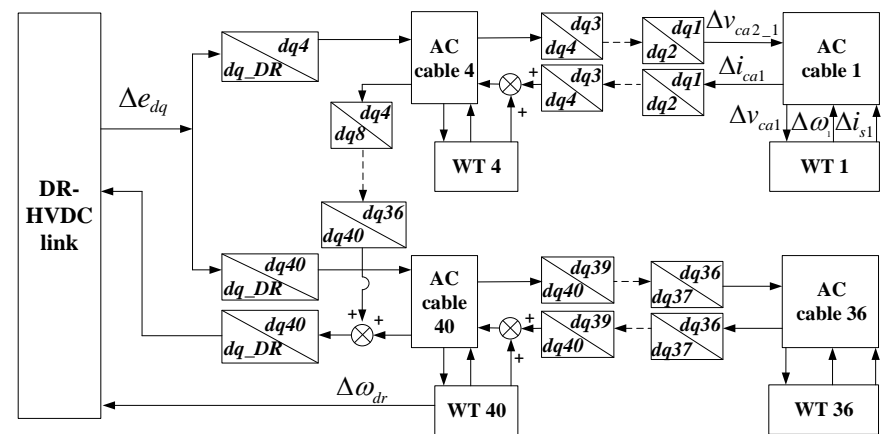

Fig. 15 Diagram of small-signal state space model of 40 WT converters connected with DR-HVDC.

\section{E. Validation of the small-signal model}

In order to validate the small-signal model, the step performances of the small-signal model in MATLAB are compared with the simulation results in PSCAD/EMTDC, when the generated active power of WTs in the first string are $25,18,15,24 \mathrm{MW}$ respectively, while the remaining $36 \mathrm{WT}$ converters all operate at full power (25 MW).

Fig. 16 shows the comparison of the responses between the time-domain PSCAD model (blue curve) and the linearized small-signal MATLAB model (red curve), when WT1 (as shown in Fig. 1) active power order decreases from its original operating point of $25 \mathrm{MW}$ by $-0.25 \mathrm{MW}$ at $0.1 \mathrm{~s}$ and WT2 reactive power order increases from its original operating point of 0 by 0.05 MVAr at $0.2 \mathrm{~s}$. As can be seen, the performances of the small-signal model are in good agreements with the results from PSCAD/EMTDC simulation.

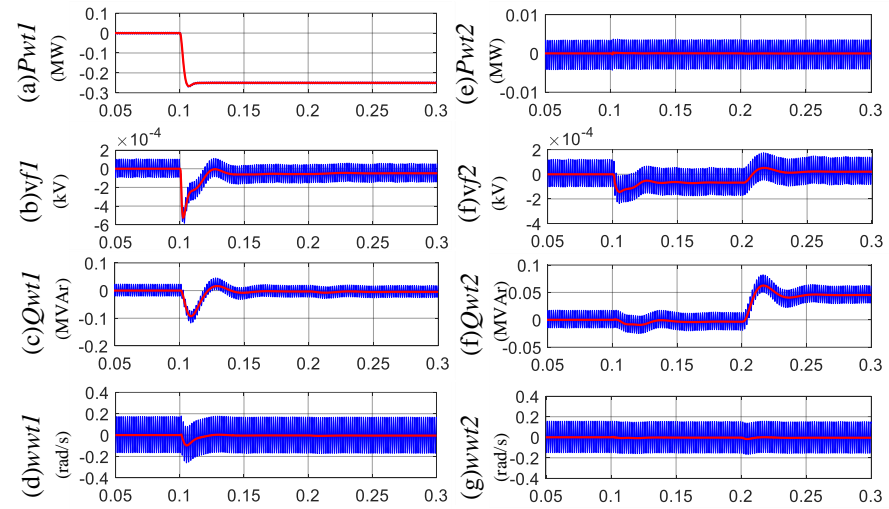

Fig. 16 Comparison between small-signal model (red) and PSCAD model (blue) during active power and reactive power change: (a) WT1 active power change; (b) WT1 AC voltage change; (c) WT1 reactive power change; (d) WT1 frequency change; (e) WT2 active power change; (f)WT2 AC voltage change; (g) WT2 reactive power change; (h) WT2 frequency change.

\section{REFERENCE}

[1] M. Zhang, X. Yuan, J. Hu, S. Wang, M. Shicong, Q. He, et al., "Wind power transmission through LCC-HVDC with wind turbine inertial and primary frequency supports," in 2015 IEEE Power \& Energy Society General Meeting, 2015, pp. 1-5.

[2] X. Chen, H. Sun, J. Wen, W. J. Lee, X. Yuan, N. Li, et al., "Integrating Wind Farm to the Grid Using Hybrid Multiterminal HVDC Technology," IEEE Trans. Ind. Appl., vol. 47, pp. 965-972, 2011.

[3] X. He, H. Geng, G. Yang, and X. Zou, "Coordinated Control for LargeScale Wind Farms with LCC-HVDC Integration," Energies, vol. 11, 2018.

[4] Vidal-Albalate R., Peña R., Belenguer E., Añó-Villalba S., Bernal-Perez R., Blasco-Gimenez R. "Simultaneous connection of type-3 and type-4 offshore wind farms to hvdc diode rectifier units", in Proceedings of the 15th Wind Integration Workshop, Vienna, Aus, 15th-17th Nov, 2016, pp. 1-6.
[5] M. Á. Cardiel-Álvarez, S. Arnaltes, J. L. Rodriguez-Amenedo, and A. Nami, "Decentralized Control of Offshore Wind Farms Connected to Diode-Based HVdc Links," IEEE Trans. Energy Convers., vol. 33, pp. 1233-1241, 2018.

[6] S. Seman, R. Zurowski, and T. Christ, " Investigation of DC Converter Nonlinear Interaction with Offshore Wind Power Park System," in EWEA Offshore Conference, Copenhagen, Denmark, 10th-12nd Mar, 2015, pp. $1-6$.

[7] P. Menke, R. Zurowski, T. Christ, S. Seman, G. Giering, T. Hammer, et al, "2nd Generation DC Grid Access for Large Scale Offshore Wind Farms," in Proceedings of the 14th Wind Integration Workshop,Brussels, Belgium, 20th-22nd Oct. , 2015, pp. 1-6.

[8] R. Blasco-Gimenez, S. Ano-Villalba, J. Rodriguez-D'Derlee, et al., "Diode-Based HVdc Link for the Connection of Large Offshore Wind Farms," IEEE Trans. Energy Convers., vol. 26, pp. 615-626, 2011.

[9] R. Blasco-Gimenez, S. Ano-Villalba, J. Rodriguez-D'Derlee, et al., "Distributed Voltage and Frequency Control of Offshore Wind Farms Connected With a Diode-Based HVdc Link," IEEE Trans. Power Electron., vol. 25, pp. 3095-3105, 2010.

[10] S. Bernal-Perez, S. Ano-Villalba, R. Blasco-Gimenez, and J. RodriguezD'Derlee, "Efficiency and Fault Ride-Through Performance of a DiodeRectifier- and VSC-Inverter-Based HVDC Link for Offshore Wind Farms," IEEE Trans. Ind. Electron., vol. 60, pp. 2401-2409, 2013.

[11] R. Blasco-Gimenez, N. Aparicio, S. Ano-Villalba, and S. Bernal-Perez, "LCC-HVDC Connection of Offshore Wind Farms With Reduced Filter Banks," IEEE Trans. Ind. Electron., vol. 60, pp. 2372-2380, 2013.

[12] L. Yu, R. Li, and L. Xu, "Distributed PLL-based Control of Offshore Wind Turbine Connected with Diode-Rectifier based HVDC Systems," IEEE Trans. Power Del., vol. 33, no. 3, pp. 1328-1336, June 2018.

[13] L. Yu, R. Li, and L. Xu, "Hierarchical control of offshore wind farm connected by parallel diode-rectifier-based HVDC and HVAC links," IET Renewable Power Generation, IET Renewable Power Generation, vol. 13, pp. 1493-1502, 2019

[14] R. Li, L. Yu, and L. Xu, "Offshore AC Fault Protection of Diode Rectifier Unit-Based HVdc System for Wind Energy Transmission," IEEE Trans. Ind. Electron., vol. 66, pp. 5289-5299, 2019.

[15] L. Yu, R. Li, and L. Xu, "Parallel operation of diode-rectifier based HVDC link and HVAC link for offshore wind power transmission," in The 7th International Conference on Renewable Power Generation (RPG2018), 2018.

[16] R. Li, L. Yu, L. Xu, and G. P. Adam, "DC Fault Protection of Diode Rectifier Unit Based HVDC System Connecting Offshore Wind Farms," in 2018 IEEE Power \& Energy Society General Meeting (PESGM), 2018, pp. $1-5$.

[17] R. Li, L. Yu, and L. Xu, "Operation of offshore wind farms connected with DRU-HVDC transmission systems with special consideration of faults," Global Energy Interconnection, vol. 1, pp. 608-617, 2018/12/01/ 2018.

[18] P. C. Krause, O. Wasynczuk, and S. D. Sudhoff, Analysis of Electric Machinery and Drive Systems, 2nd ed. Piscataway, NJ: IEEE Press, 2002.

[19] C. Osauskas and A. Wood, "Small-signal dynamic modeling of HVDC systems," IEEE Transactions on Power Delivery, vol. 18, pp. 220-225, 2003.

[20] X. Ni, A. M. Gole, C. Zhao and C. Guo, "An Improved Measure of AC System Strength for Performance Analysis of Multi-Infeed HVdc Systems Including VSC and LCC Converters," IEEE Trans. Power Del., vol. 33, no. 1, pp. 169-178, Feb. 2018.

[21] J. Rocabert, A. Luna, F. Blaabjerg, and P. Rodríguez, "Control of Power Converters in AC Microgrids," IEEE Trans. Power Electron., vol. 27, pp. 4734-4749, 2012.

[22] L. P. Kunjumuhammed, B. C. Pal, R. Gupta, and K. J. Dyke, "Stability analysis of a PMSG-based large offshore wind farm connected to a VSCHVDC," IEEE Trans. Energy Convers., vol. 32, no. 3, pp. 1166-1176, Sep. 2017.

[23] H. Huang, C. Mao, J. Lu, and D. Wang, "Small-signal modelling and analysis of wind turbine with direct drive permanent magnet synchronous generator connected to power grid," IET Renew. Power Generation, vol. 6, no. 1, pp. 48-58, Jan. 2012.

[24] N. Pogaku, M. Prodanovic, T. C. Green, "Modeling, analysis and testing of autonomous operation of an inverter-based microgrid," IEEE Trans. Power Electron., vol. 22, no. 2, pp. 613-625, Mar. 2007. 


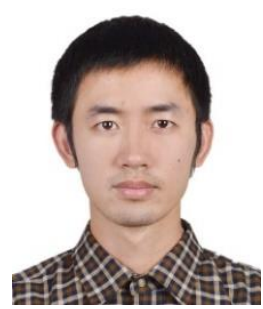

Lujie Yu received the B.S. degree from North China Electric Power University (NCEPU), Baoding, China, in 2012, M.S. degree from NCEPU, Beijing, China, in 2015, Ph.D degree in Electronic \& Electrical Engineering, University of Strathclyde, Glasgow, UK in 2019. Currently, he is a lecturer with School of Electrical and Information Engineering, Tianjin University, Tianjin, China.

His research interests include HVDC transmision system and wind power integration.

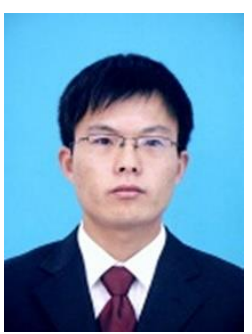

Rui Li received the M.S. and Ph.D degrees in electrical engineering from Harbin Institute of Technology, Harbin, China, in 2008 and 2013, respectively. $\mathrm{He}$ is a researcher with University of Strathclyde in Glasgow, UK, since 2013.

His research interests include HVDC transmision system, grid integration of renewable power, power electronic converters, and energy conversion.

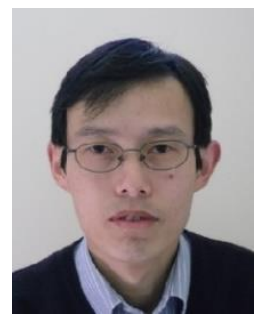

Lie Xu (M'03-SM'06) received the B.Sc. degree in Mechatronics from Zhejiang University, Hangzhou, China, in 1993, and the Ph.D. degree in Electrical Engineering from the University of Sheffield, Sheffield, UK, in 2000.

He is currently a Professor at the Department of Electronic \& Electrical Engineering, University of Strathclyde, Glasgow, UK. He previously worked in Queen's University of Belfast and ALSTOM T\&D, Stafford, UK. His research interests include power electronics, wind energy generation and grid integration, and application of power electronics to power systems. He is an Editor of IEEE Transactions on Power Delivery and IEEE Transactions on Energy Conversion.

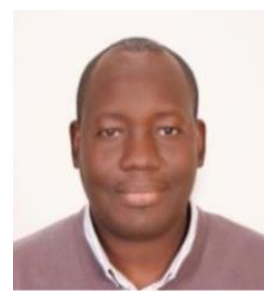

Grain P. Adam (M'12) received the B.Sc. and M.Sc. degrees (Hons.) from Sudan University for Science and Technology, in 1998 and 2002 respectively; and a $\mathrm{PhD}$ in Power Electronics from University of Strathclyde in 2007 . He is a researcher with University of Strathclyde in Glasgow, UK, since 2008. His research interests are fault tolerant voltage source converters for HVDC applications; modelling and control of HVDC transmission systems and multiterminal HVDC networks; voltage source converter based FACTS devices; and grid integration issues of renewable energies. Dr. Adam has authored and coauthored several technical reports, and over 100 journal and conference articles. Dr. Adam has published two books in applications of power electronics in power systems and renewable energy. He is an active contributor to reviewing process for several IEEE and IET Transactions, Journals and conferences, and a member of IEEE. He is an Associate Editor of Journal of Emerging and Selected Topics in Power Electronics. 